Session Number: 1475

\title{
The ESTEeM Project: Collaborative Learning and Teaching of Engineering Mathematics at the Faculty of Engineering, University of Santo Tomas, Manila
}

\author{
Cristino A. Carbonell, Clarita R. Guevara, Fe P. Tabamo \\ Faculty of Engineering, University of Santo Tomas
}

\section{Introduction}

Information and Communications Technology (ICT) has largely changed the learning environment in today's world. There are now several options presented in the learning environment on how easily and more excitingly knowledge can be acquired. Learning institutions worldwide have recognized the tremendous influence the new technology has over its clients - the teachers and the students. It is for this reason that learning institutions unceasingly introduce innovations in the course curricula.

The breakthroughs in ICT have changed the learning scenario. Its impact on education, and on society as a whole, cannot be ignored ${ }^{1}$.

- ICT is an agent of change. It has dramatically transformed our daily life and work. There are new professions, new economic frameworks, and new educational programs continuing studies or lifelong learning and multimedia.

- ICT means an e-literate society. A new society emerges. It is a society where everybody should know, acquire skills and perform activities required of the technology.

- ICT requires e-learning. Educators, teachers, trainers and their students are expected to use ICT in more imaginative and creative ways. Authoring systems, intelligent tutor agents and collaborative environments are just some of the novel means by which the full potential of ICT may be explored.

- ICT provides paradigms shift in education. The integration of ICT in education has allowed the transformation of the educator from being a lecturer and provider of information to being a guide, an adviser and a motivator.

The Engineering Sciences Department of the Faculty of Engineering of the University of Santo Tomas, Manila, Philippines, has seen the opportunity of integrating ICT in the delivery of some of its Mathematics courses. The utilization of different software like Macromedia's Flash and Adobe Photoshop in courses like College Physics or Differential Calculus will definitely enhance the presentation of various concepts. Learning materials will be highly visual and more interesting especially when animated diagrams are presented. The introduction of external links will allow for a wider perspective of the concepts learned. The World Wide Web will provide the learner with a voluminous source of information making him more informed and updated with new developments and discoveries. Learning will never be the same again. 
The International Federation for Information Processing [IFIP], in its World Conference on Computers in Education in 1995, expressed that development in education is brought about by development in society. ICT has changed the educational organization, the learning content, the institution's infrastructures, and the competency requirements. At that time, IFIP saw the unavoidable integration of ICT in education ${ }^{2}$.

The IBM Series on Living in the Information Society has presented the CircuitTutor of the University of Illinois at Urbana-Champaign and Project Vision of the Pennsylvania State University $^{3}$. The CircuitTutor is a software package utilized by the students of the ECE270 course at the University of Illinois at Urbana-Champaign to carry out homework drills after attending lectures. Project Vision of the Pennsylvania State University makes students work in local and multi-campus teams to complete a course based on a combination of guided worldwide web search, personalized mentoring via e-mail and group conferencing and team projects.

In Munich, Germany, four federal schools are participating in the SEMIK (Systematic Integration of Media and ICT in Teaching and Learning) Project where student teachers create and edit pictures, video and sound; and present the output in a multimedia document ${ }^{4}$. At the University of Koblenz-Landau, the In2Math software has been designed to support undergraduate education in Mathematics and theoretical computer science. The project involves 10 partners from 4 universities and another 4 industrial partners 5 .

Secondary schools worldwide follow the same trend. In the city of Solothurn in Switzerland, every teacher of all the secondary schools is provided a notebook by the government for online teaching during class hours ${ }^{6}$. The use of animation in the teaching of elementary pupils has been implemented through the IVTE (Intelligent Virtual Teaching Environment) project designed by the Distance Learning Group of the Engineering and Computer Science Departmnent at the URI University in Brazil ${ }^{7}$. In the Feruniversitat Hagen at Holzkamp-Gesamtschule Witten, Germany, fifth graders are required to come up with a multimedia visual model, employing Flash 5, of a scenery the students have observed ${ }^{8}$. The introduction of more user-friendly software in the market has encouraged educators worldwide to utilize available technologies to enhance and support the teaching and learning activities.

\section{Rationale for Using Technology in Education}

Technology has posed a challenge to educators to introduce innovations in the educational materials to promote better learning. But there is a question on the viability of integrating the technology. Is it really needed? Is it effective?

Research has been undertaken on the effectiveness of technology in education. Conflicting results were obtained by different groups which conducted such research ${ }^{9}$. One set of findings led to the conclusion that technology is indeed more effective in bringing about learning. Another school of thought concluded that there was not a significant difference between learning with the integration of technology and without the use of the technology. However, it cannot be denied that the use of technology will provide benefits to both the teacher and the learner despite all the questions and issues raised against it. 
These are some rationale on using technology in education ${ }^{9}$ :

- Motivation

Attention can be gained by designing lessons that are more fun and exciting. The learner is actively engaged in activities that promote creativity and self-expression. The learner dictates his pace in learning the course. The perception of control develops selfconfidence and self-fulfillment.

- Unique Instructional Capabilities

The technology links the learner to information sources and learning tools allowing him to better visualize problems and their solutions.

- Support for New Instructional Approaches

Collaborative learning is the approach employed by various educators integrating ICT in the teaching of courses. This approach promotes teamwork, intellectual collaboration and sharing of knowledge.

- Increased Teacher Productivity

The development of multimedia instructional materials will provide the teacher more time to work with the students, give more accurate information more quickly, and produce more "student-friendly" learning materials.

IV The ESTEeM (Engineering Sciences Teacher's Educational e-Material) Project

The University of Santo Tomas (UST) prides itself as the oldest learning institution in the country. It is a university that is rich with a glorious past and continues to reap honors through its highly competent and socially ethical graduates. In 2011, UST celebrates its fourth centennial.

The Faculty of Engineering of UST, on the other hand, boasts itself as the oldest engineering institution in the Philippines. 2007 marks its first centennial as a center for excellent engineering education. UST and its Faculty of Engineering see the need to meet the challenges of ICT and the knowledge explosion the world is experiencing. The UST Educational Technology Center (UST EdTech), the media production and information technology center of the university, provides the link between the rich tradition that UST and the Faculty of Engineering have nurtured and the future that everyone looks forward to.

The ESTEeM Project is undertaken by the Engineering Sciences (ES) Department as a response to the challenges posed by ICT in the academic milieu. It hopes to provide a different kind of learning and teaching material for UST students to have fun and excitement while going through a course. The project involves the production of interactive learning materials in three Mathematics Courses, namely, Solid Geometry, Differential Calculus and College Physics 1. These materials are support materials to enhance teaching and learning and are not meant as stand-alone materials.

- Learning Theories ${ }^{9}$

Skinner's learning model about the learning stimulus and the provision of positive reinforcements leading to repeated response will be the basic framework in the development of the interactive exercises and activities in the learning materials.

The view of the Information-Processing theorists that the mind is a computer cannot be ignored. It hypothesizes that the human brain has three kinds of memory: the sensory 
registers, the short-term memory (STM) and the long-term memory (LTM). The model describes information entering the brain as follows: anything a person senses will enter into his STM if attention was given upon reception, and if processed within 5 to 20 seconds, may enter into his LTM and remain there for a long time or maybe lost if not regularly used.

Thus, the design of the learning materials must be anchored on providing a good stimulus to learners to capture and sustain their interests with the use of graphics, video and sound; provide assessment and immediate feedback; employ games and simulations; and direct them to relevant and interesting links.

- Project Plan

The ESTEeM Project Management Methodology is largely based on the TIER (Teacher Interactive Educational Resource) Management Methodology of the UST TIER Project. The ESTEEeM Project is an offshoot of the training program given by the UST EdTech Center to selected faculty members of the University during the Summer Session of 2002.

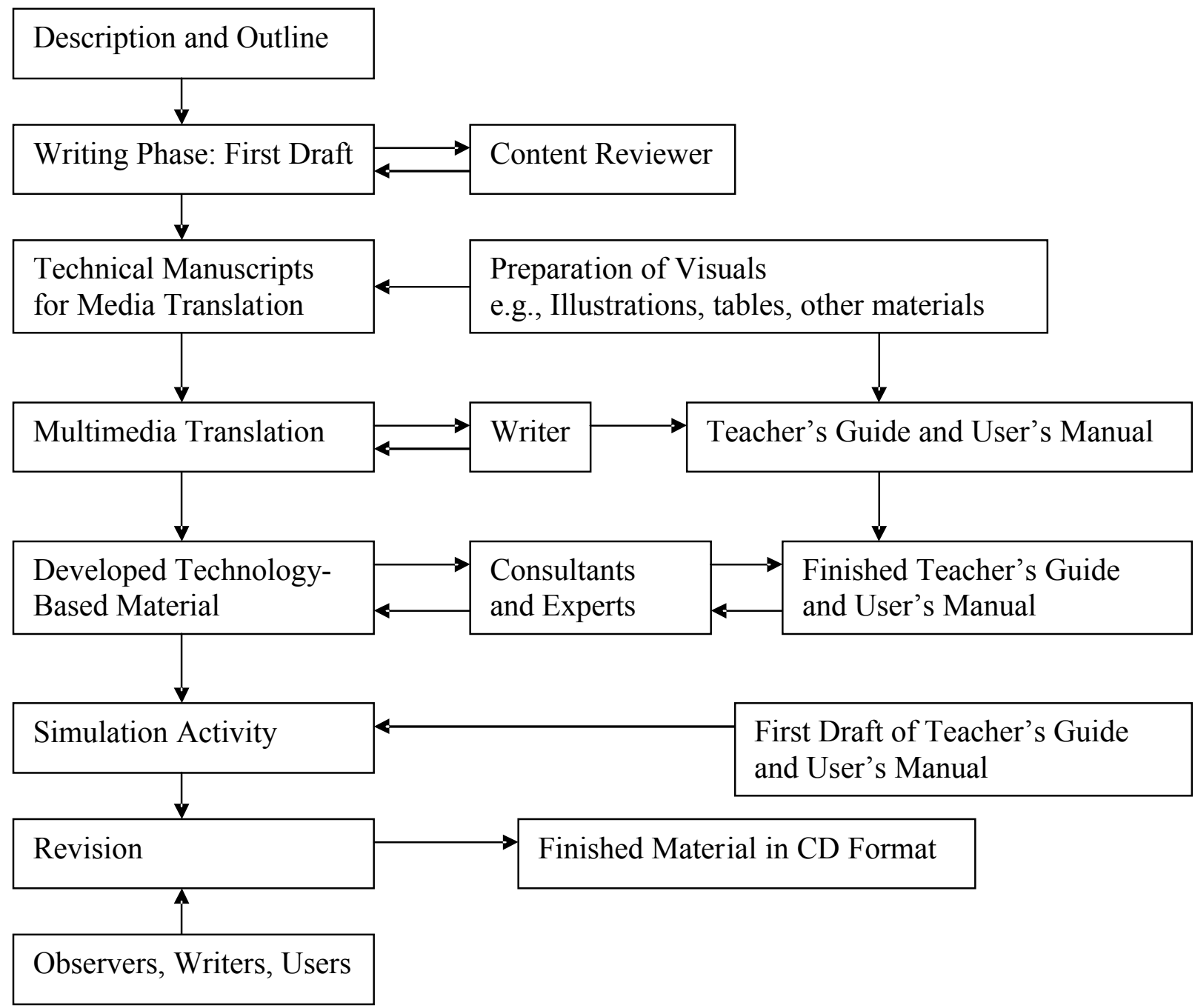

FLOWCHART FOR DEVELOPING INSTRUCTIONAL MATERIALS 
The flowchart for developing e-Learning materials of the UST TIER Project is also adopted by the ESTEeM Project ${ }^{10}$.

The project allows for collaboration among the teaching staff. A project leader is assigned for every course. A content expert, a research expert and a technology expert complete the team. The content expert is tasked to design the contents that the lessons in the material will cover. A concept map is required to be able to guide and help the content expert with the relationships of concepts involved in the lesson. The research expert will provide the various sources where discussion of the content, graphics, related links and all other resources relevant to the lesson are obtained. It is ideal that both experts work hand-in-hand. The content reviewer goes through the concept map before a technical manuscript is drafted.

A technical script is produced to give directions to the technology expert when the project reaches its translation stage. It is expected that the content expert regularly exchange views with the technology expert to ensure that what appears in the final material will be true to what is listed on the technical script. The learning material must provide interesting discussions, illustrative examples, assessments and web-based activities to allow for collaborative learning among students. Thus, in the development of the technical script into a multimedia material, the Adobe Photoshop and Illustrator, Macromedia Flash and Swish software will be applied. Adobe Photoshop edits and enhances photographs. Adobe Illustrator allows the technology expert to create and paint different illustrations. Macromedia Flash may animate the diagrams produced. Flash can also create inter-active learning activities. Swish is used to present the text of the presentation in a very different way to attract learner's attention.

As the translation of the technical script is in progress, the content and research experts will prepare the draft of the Teacher's Guide and the User's Manual. These will serve as guides of the other members of the staff teaching the course and the students who will use the interactive materials. Consultants and experts review both the developed material and the finished guides.

Simulation takes place after the review. Selected students and members of the academic community will act as roles of learners in the simulation and evaluate the effectiveness on the learning material produced. Revision may follow. A second simulation may be required.

Initially, the project requires every group to produce a multimedia material for one lesson of the course only. It is envisioned that a full-blown learning material may be produced later on. Caution is taken in selecting the lessons that will use multimedia. The project realizes the limitation of the technology. Only where appropriate, relevant and useful, may the technology be integrated.

The first phase of the ESTEeM Project involves the production of the concept map of a selected lesson. Training sessions on the different software are scheduled during the Summer Session. The technical script is developed after the training. This phase commences after the mid-term exam in January, 2003 and ends on the second week of April, 2003. 
The second phase involves the translation of the script into the developed material and the drafts of the Teacher's Guide and user's Manual. The technical expert is expected to work with the personnel of the UST EdTech Center for polishing of the translated material. The content and research experts are required to work closely with the Chair of the ES Department who acts as Consultant. This phase ends on June, 2003.

The final phase of the project is carried out during the first semester of the school year. The developed material is simulated. The assessment material is prepared to evaluate the effectiveness of the material in terms of content and presentation style. Revision will be done based upon the recommendation of the participating students and experts.

\section{Conclusion}

The Engineering Sciences of the Faculty of Engineering has been spearheading instructional innovations at the University of Santo Tomas. Independent learning modules at UST were first developed at the Faculty of Engineering by the ES Department in 1998. It is now undertaking the production of e-Learning materials in the university in response to the university's vision of the university's desire to have some, if not all, courses online.

However, certain issues are still raised.

- Will the technology guarantee the development of a better teacher?

- Will the technology guarantee the development of a better learner?

- Is technology a threat to the continued existence of the teaching staff?

- Does the technology make the teacher obsolete?

- How much will it cost the learner to avail of the technology?

ICT concretizes the idea that learning never ends. Learning is eternal. And learning is not only for students, but also for practitioners, professionals, and even teachers! The society we are in is a very dynamic one. It is incumbent upon us, educators, to update with the present trends and developments; to continue the search for new teaching/learning activities; and to exercise the imagination to create innovative materials. These will ensure that the students whom we have trained and molded are industry-competent and ready to serve the world.

\section{BIBLIOGRAPHY:}

${ }^{1}$ Schubert, S.: Book of Abstracts, SEC III - Open IFIP-GI-Conference on Social, Ethical and Cognitive Issues of Informatics and ICT, Germany, 2002

${ }^{2}$ Adams, P.E., et al.: "Strategies for Implementing Computer Technology in the Classroom”, Issues in Education, 1996

${ }^{2}$ Weert, T.: IFIP Working Group 3.1: Towards Integration of Computers in Education, World Conference on Computers in Education VI, UK, 1995

${ }^{3}$ IBM Series on Living in the Information Society: "Transforming Higher Education", http://www-1.ibm.com/industries/education/pdf/higher.pdf . 2001

${ }^{4}$ Schumacher, F.: "Practical Use of Multimedia in Teacher Training', SEC III Conference on Informatics, Germany, 2002 
5 Baumgartner P.: 'In2Math - Interactive Elements in Mathematical and Computer Science Education", SEC III Conference on Informatics, Germany, 2002

${ }^{6}$ Honegger, D.: “One Notebook per Teacher: A Sustainable Concept for a Wide ICT Integration in School”, SEC III Conference on Informatics, Germany, 2002

${ }^{7}$ Nunes, M.A., et al.: “Animated Pedagogical Agent in a Learning Environment”, SEC III Conference on Informatics, Germany, 2002

${ }^{8}$ Weigend, M.: "Development of Multimedia Animations - A Contribution of Informatics to Media Studies", SEC III Conference on Informatics, Germany, 2002

${ }^{9}$ Roblyer, M. et al: Integrating Educational Technology into Teaching, Prentice Hall, NJ, 1995

10 “TIER Management Methodology and Maximization of the World Wide Web", TIER Training Program Customized for University of Santo Tomas, 2002.

\section{BIOGRAPHICAL INFORMATION}

Associate Professor CRISTINO A. CARBONELL is an Electrical Engineering graduate of the University of Santo Tomas. He obtained his Master's Degree in Electrical Engineering Education from the University of the Philippines, Diliman, Quezon City. He was a Visiting Fellow at the University of New South Wales in Sydney, Australia where he took courses on Optimization and Power Operation, Generation and Control. He attended ISTAS 00, Rome, Italy and presented papers at the ISTAS 01, Connecticut, USA, ICEE 2002, Manila, Philippines and SEC III, Dortmund, Germany. He is the Phyhsics Laboratory Supervisor of the UST Faculty of Engineering.

Associate Professor CLARITA R. GUEVARA is a Chemical Engineering graduate of the University of Santo Tomas. She obtained her Master's Degree in Industrial Engineering from the University of the Philippines, Diliman, Quezon City. She was a Visiting Fellow at the University of New South Wales in Sydney, Australia where she attended courses on Advanced Engineering Mathematics and Numerical Methods. She co-presented a paper at the ICEE 2002, Manila,Philippines. She is the Chair of the Enginering Sciences Department of the UST Faculty of Engineering.

Associate Professor FE P. TABAMO is a Chemical Engineering graduate of the University of Santo Tomas. She obtained her Master's degree in Chemistry Education from the Graduate School of the University of Santo Tomas. She co-presented a paper at the ICEE 2002, Manila, Philippines. She is the Computer Coordinator of the UST Faculty of Engineering.

Proceedings of the 2003 American Society for Engineering Education Conference and Exhibition@2003, American Society for Engineering Education 